\title{
Perencanaan Peningkatan Tebal Perkerasan Lentur Pada Ruas Jalan Petuk (STA 15+050 - STA 15+500) Kec. Penfui Kota Kupang Menggunakan Metode Bina Marga 2017
}

\author{
Pandji Thoha S. Balido'), Sri Wiwoho Mudjanarko'), Hendramawat Aski \\ Safarizki $^{3}$ ** \\ 1)2) Fakultas Teknik, Program Studi Teknik Sipil, Universitas Narotama Surabaya Jl. Arif Rahman Hakim \\ 51 Surabaya.Email: tohapanji@gmail.com, sri.wiwoho@narotama.ac.id \\ ${ }^{3)}$ Fakultas Teknik, Program Studi Teknik Sipil, Universitas Veteran Bangun Nusantara, Sukoharjo, J1. \\ Letjen Sudjono Humardhani, No.1, Jombor, Sukoharjo; Telp. 0271-593156. Email: \\ hendra.mawat@gmail.com*
}

\begin{abstract}
Abstrak
Perkerasan lentur (flexible pavement) adalah sistem perkerasan jalan dimana konstruksi terdiri dari beberapa lapisan. Tiap-tiap lapisan perkerasan pada umumnya menggunakan bahan maupun persyaratan yang berbeda sesuai dengan fungsinya yaitu, menyebarkan roda kendaraan sedemikian rupa sehingga dapat ditahan oleh tanah dasar. Aspal sebagai bahan pengikat merupakan material penting dalam konstruksi perkerasan jalan. Perkerasan jalan di Indonesia sebagian besar menggunakan aspal minyak dengan Penetrasi 60/70. Akan tetapi penggunaan aspal konvensional masih memiliki kelemahan, salah satunya adalah perkerasan jalan tidak mampu menahan beban lalu lintas berlebih dan temperatur tinggi. Penggunaan Asbuton modifikasi (Retona) diharapkan dapat mengatasi kelemahan aspal konvensional tersebut. Aspal Retona dikembangkan melalui proses penyulingan dan ekstraksi Asbuton guna mempertinggi kualitas aspal. Penelitian ini dilakukan di laboratorium PT. Alam Indah Cendana Lestari, Kota Kupang. Penelitian ini bertujuan untuk mengevaluasi kinerja terhadap ruas jalan petuk. Perkerasan jalan tidak mampu menahan beban lalu lintas berlebih dan temperatur tinggi. Perencanaan perkerasan jalan ini adalah untuk mendapatkan tebal struktur perkerasan lentur dengan menggunakan metode Bina Marga 2017.
\end{abstract}

Kata kunci: Perkerasan lentur, Analisis perkerasan, Perencanaan jalan.

\begin{abstract}
Flexible pavement is a road pavement system where the construction consists of several layers. Each layer of pavement generally uses different materials and requirements according to its function, namely, spreading the wheels of the vehicle in such a way that it can be held by the subgrade. Asphalt as a binder is an important material in road pavement construction. Most of the road pavements in Indonesia use oil asphalt with a Penetration of 60/70. However, the use of conventional asphalt still has weaknesses, one of which is the road pavement is not able to withstand excessive traffic loads and high temperatures. The use of modified Asbuton (Retona) is expected to overcome the weakness of conventional asphalt. Asphalt Retona was developed through the process of refining and extracting Asbuton in order to enhance the quality of the asphalt. This research was conducted in the laboratory of PT. Beautiful Nature Cendana Lestari, Kupang. This study aims to evaluate the performance of the Petuk road segment. Road pavement is not able to withstand excessive traffic loads and high temperatures. The design of this road pavement is to obtain the thickness of the flexible pavement structure using the 2017 Highways method.
\end{abstract}

Keywords: Flexible pavement, Pavement analysis, Road planning.

\section{PENDAHULUAN}

Transportasi adalah salah satu kebutuhan dan kepentingan keseluruhan manusia yang disebabkan oleh adanya suatu sistem pergerakan atau perpindahan obyek, baik berupa manusia ataupun barang dari suatu tempat asal ketempat perpindahan tujuan yang dikehendaki. Transportasi memegang peranan penting dalam pelaksanaan pembangunan dan pengembangan daerah disegala bidang, sehingga diperlukan suatu perencanaan jalan agar benar-benar berfungsi sebagai sarana transportasi (Pratama Yoga, 2017).

Transportasi terdiri dari komponen lalulintas dan perkerasan jalan. Perkerasan jalan raya adalah bagian jalan raya yang diperkeras dengan lapis konstruksi tertentu, yang memiliki ketebalan, kekuatan, dan kekakuan, serta 
kestabilan tertentu agar mampu menyalurkan beban lalu lintas diatasnya ke tanah dasar secara aman. Agar perkerasan jalan yang sesuai dengan mutu yang diharapkan, maka pengetahuan tentang sifat, pengadaan dan pengolahan dari bahan penyusun perkerasan jalan sangat diperlukan (Harold N. Atkins, PE. 1997).

Perkerasan lentur adalah perkerasan yang menggunakan aspal sebagai bahan pengikat. Pada umumnya perkerasan lentur baik digunakan untuk jalan yang melayani beban lalu lintas ringan sampai sedang, seperti jalan perkotaan, jalan dengan system ultilitas terletak di bwah perkerasan jalan, perkerasan bahu jalan, atau perkerasan dengan konstruksi bertahap. Berikut merupakan konstruksi perkerasan lentur tiap lapisnya. (Sukirman, 1999)

\section{Lapis Permukaan (Surface Course) \\ 2. Lapis Pondasi Atas (Base Course) \\ 3. Lapis Pondasi Bawah (Subbase Course) \\ 4. Tanah Dasar (Subgrade)}

Perkerasan jalan dalam masa layannya akan mengalami degradasi kemampuan dalam menerima beban lalulintas. Kemampuan perkerasan dalam menerima beban berkaitan dengan kapasitas pada masa layan jalan. Menurut buku Standar Geometrik Jalan Perkotaan yang dikeluarkan oleh Direktorat Jendral Bina Marga, kapasitas didefinisikan sebagai arus maksimum melalui suatu titik di jalan yang dapat dipertahankan per satuan jam pada kondisi tertentu.

Perbaikan perkerasan lentur yang diterapkan di Indonesia memasuki tahapan kritis terutama pada jalan raya, dimana perbaikan hanya dilakukan dengan model "kearifan lokal" tanpa mempertimbangkan model perbaikan berdasarkan tipe kerusakan yang terjadi (Sri Wiwoho dkk, 2017).

Kondisi jalan di Petuk ini bisa dibilang kurang memadai, hal ini dikarenakan kondisi saat ini jalannya yang sudah rusak. Kondisi ini membuat masyarakat dan pengguna jalan merasa tidak nyaman untuk melakukan aktifitas transportasi, karena sering terhambat oleh kondisi jalan tersebut. Menurut klasifikasi jalan Desa Petuk ini tergolong jalan lokal, dan jalan ini merupakan akses jalan tercepat dari pelabuhan menuju ke Bandara El Tari Kupang. Untuk mengatasi kondisi tersebut dibangun atau direncanakan ulang jalan yang ada di Desa Petuk dengan perkerasn lentur menggunakan Metode Bina Marga 2017.

Dengan memperhatikan hal-hal yang telah dijelaskan sebelumnya, maka masalah yang akan dibahas adalah berapa tebal perkerasan yang diperlukan untuk umur rencana jalan (UR) 20 tahun dengan menggunakan metode Bina marga 2017. Selanjutnya dilakukan pula perhitungan kapasitas jalan dengan umur rencana 20 tahun. Dan terkahir menghitung nilai rencana anggaran biaya untuk pembangunan jalan tersebut.

\section{METODE}

Penelitian dilakukan dengan mengikuti alur penelitian seperti tampak pada Gambar 1.

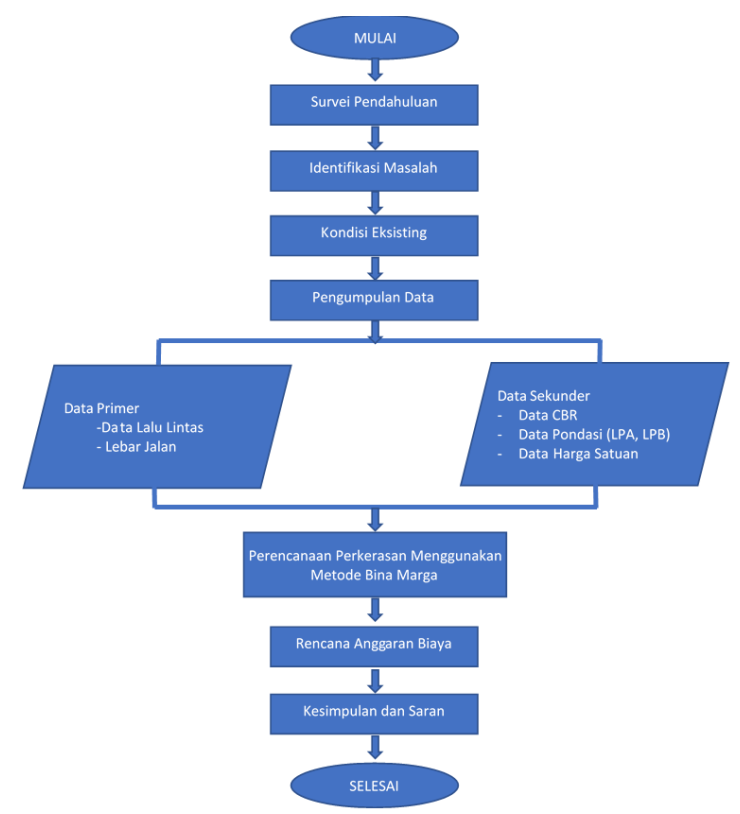

Gambar 1. Diagram Alir Penelitian

\section{Rencana Anggaran Biaya}

Rencana anggaran biaya (RAB) berisikan tentang besarnya volume pekerjaan, serta biaya pekerjaan. Besarnya volume perkerjaan dihitung dari volume tiap item pekerjaan, sedangkan biaya pekerjaan ditentukan dari harga upah pekerjaan, harga bahan, analisa tiap item pekerjaan, dan harga penggunaan alat berat yang digunakan, dari pengolahan data tersebut ditambah keuntungan dan biaya PPN dalam pelaksanaan pekerjaan. Rumusan perhitungan RAB secara umum dapat dituliskan sebagai berikut :

$R A B=\sum($ Volume $x$ Harga Satuan Pekerjaan $) \ldots . .(1)$

Dalam menyusun anggaran biaya dibutuhkan data volume pekerjaan dan harga satuan 
pekerjaan.Metode penelitian berisi bahanbahan utama yang digunakan dalam penelitian dan metode-metode yang digunakan dalam pemecahan permasalahan termasuk metode analisis.

\section{HASIL DAN PEMBAHASAN}

Ruas jalan Desa Petuk, Kecamatan Penfui Kota Kupang merupakan jalan Nasional dengan tipe jalan 2 jalur, 2 arah. Lebar jalan $11 \mathrm{~m}$ yang terdiri dari jalur lalu lintas $7 \mathrm{~m}$ dan lebar bahu jalan kiri - kanan $2 \mathrm{~m}$ sesuai dengan persyaratan teknis jalan untuk ruas jalan dalam system jaringan jalan primer peraturan pekerjaan umum nomor 19 tahun 2011.

\section{Data Lalu-lintas}

Pertumbuhan Lalu-lintas Harian Rata-rata Ruas Jalan Petuk Kecamatan Penfui Kota Kupang pada setiap tahunnya diketahui berdasarkan hasil survey dan pengolahan data pada dinas terkait seperti tampak pada Tabel 1.

Tabel 1. Pertumbuhan Lalu-lintas Harian Ratarata Ruas Jalan Petuk Kecamatan Penfui Kota Kupang Tahun 2017-2019

\begin{tabular}{llrrr}
\hline No & Jenis kendaraan & \multicolumn{2}{c}{ (unit) } & \multicolumn{2}{c}{ (unit) } & \multicolumn{1}{c}{ (unit) } \\
\hline 1 & Bus & 197 & 258 & 268 \\
2 & Mobil Pribadi & 12984 & 14656 & 15661 \\
3 & Sepeda Motor & 146931 & 183989 & 197211 \\
4 & Truk & 6045 & 6766 & 7107 \\
& Jumlah & 166193 & 205717 & 220303
\end{tabular}

Sumber data : BPS Kota Kupang

$\mathrm{i}=\frac{\mathrm{LHR}_{\mathrm{n}-1}-\mathrm{LHR}_{\mathrm{n}}}{\mathrm{LHR}_{\mathrm{n}}} \times 100 \%$

Jumlah kendaraan per tahun :

1. LHR tahun $2017=166193$ kendaraan

2. LHR tahun $2018=205717$ kendaraan

3. LHR tahun $2019=220303$ kendaraan

Total jumlah kendaraan adalah $=592213$ kendaraan

Pertumbuhan lalu lintas (i) tahun 2017-2019

Tahun 2017, i $=\frac{166193}{592213} \times 100 \%=28,06 \%$

Tahun 2018, $\mathrm{i}=\frac{205717}{592213} \times 100 \%=34,73 \%$

Tahun 2019, $\mathrm{i}=\frac{220303}{592213} \times 100 \%=31,19 \%$

Pertumbuhan rata-rata setiap kendaraan (\%) setiap tahunnya.

Tahun $2018-2017=34,73-28,06=6,67 \%$ Tahun $2019-2018=31,19-34,73=-3,54 \%$ i rata-rata $=\frac{6,67+(-3,54)}{2}=1,565 \%$

\section{Volume Lalu-lintas}

Data LHR diperoleh langsung dari pengamatan di lapangan, volume lalu lintas ini akan digunakan untuk keseluruhan segmen yaitu, segmen1, segmen2, segmen3, dan segmen rencana. Untuk lebih jelasnya LHR yang diperoleh dari pengamatan di lapangan dapat dilihat pada Tabel 2 di bawah ini.

Tabel 2. Kendaraan Yang Melintas Di Jalan Petuk Kecamatan Penfui, (Kend/Hari).

\begin{tabular}{lcl}
\hline \multicolumn{1}{c}{$\begin{array}{c}\text { Jenis } \\
\text { kendaraan }\end{array}$} & Jumlah & satuan \\
\hline Bus & 16 & Kend/hari \\
Sepeda motor & 550 & Kend/hari \\
Mobil pribadi & 183 & Kend/hari \\
Truk & 23 & Kend/hari \\
Jumlah total & 772 & Kend/hari \\
& & \\
\hline
\end{tabular}

Tabel 3. Jumlah LHR Kendaraan Dengan Berat Total $>2$ ton

\begin{tabular}{lcl}
\hline $\begin{array}{c}\text { Jenis } \\
\text { kendaraan }\end{array}$ & Jumlah & satuan \\
\hline Bus & 16 & Kend/hari \\
Mobil pribadi & 183 & Kend/hari \\
Truk & 23 & Kend/hari \\
Jumlah total & 772 & Kend/hari
\end{tabular}

Dari data tersebut dapat kita cari besarnya lalu lintas harian rata-rata umur rencana. $\left(\mathrm{LHR}_{\mathrm{t}}\right)$.

a. LHR pada awal umur rencana

LHR $_{0}$ pada awal umur rencana dapat dicari dengan menggunakan persamaan berikut ini :

$\mathrm{LHR}_{0}=(1+\mathrm{i})^{\mathrm{n}} \times \mathrm{LHR}_{\mathrm{p}}$

Dimana :

$\mathrm{i}=$ pertumbuhan lalu lintas rata-rata $=0,01565$

$\mathrm{n}=$ selama masa pelaksanaan 1 tahun

$\mathrm{LHR}_{\mathrm{p}}$ diambil dari setiap jenis kendaran adalah sebagai berikut:

Sepeda motor $=(1+0,01565)^{1} \times 550=559$

kendaraan

Bus $\quad=(1+0,01565)^{1} \times 16=17$

kendaraan

Mobil pribadi $=(1+0,01565)^{1} \times 183=186$

kendaraan

Truk $=(1+0,01565)^{1} \times 23=24$

kendaraan

Jumlah

$=786$ kendaraan 
b. LHR pada akhir umur rencana

$\mathrm{LHR}_{\mathrm{t}}$ akhir umur rencana ini dapat dicari dengan menggunakan persamaan sebagai berikut:

$\mathrm{LHR}_{\mathrm{t}}=(1+\mathrm{i})^{\mathrm{UR}} \mathrm{x} \mathrm{LHR}_{\mathrm{p}}$

Dimana :

$\mathrm{i}=$ pertumbuhan lalu lintas rata-rata $=0,01565$

$\mathrm{UR}=$ umur rencana 20 tahun

$\mathrm{LHR}_{\mathrm{p}}$ diambil dari setiap jenis kendaraan adalah sebagai berikut :

Sepeda motor $=(1+0,01565)^{20} \times 550=751$

kendaraan

Bus $\quad=(1+0,01565)^{20} \times 16=22$ kendaraan Mobil pribadi $=(1+0,01565)^{20} \times 183=250$

kendaraan

Truk $=(1+0,01565)^{20} \times 23=32$ kendaraan Jumlah

$$
=1055 \text { kendaraan }
$$

\section{Analisa Perhitungan Lapisan Perkerasan jalan Untuk Metode Bina Marga}

Pengolahan data hasil perhitungan segmen rencana disajikan dalam bentuk tabel sebagai berikut:

Tabel 4. Indeks Tebal Minimum Perkerasan Pada Jalan Petuk

\begin{tabular}{|c|c|c|c|c|c|}
\hline segmen & $\begin{array}{l}\text { Lapisan } \\
\text { Perkerasan }\end{array}$ & $\begin{array}{l}\text { Nilai } \\
\text { ITP }\end{array}$ & $\begin{array}{l}\text { Tebal } \\
\text { Maksimum }\end{array}$ & $\begin{array}{l}\text { Jenis } \\
\text { Bahan }\end{array}$ & $\begin{array}{l}\text { Kekuatan } \\
\text { Relatif } \\
\text { Bahan }\end{array}$ \\
\hline \multirow{3}{*}{$\begin{array}{l}\text { (STA } \\
15+050 \\
-\quad \text { STA } \\
15+500)\end{array}$} & $\begin{array}{l}\text { Lapisan } \\
\text { permukaan }\end{array}$ & & 10 & $\begin{array}{l}\text { Laston } \\
744 \mathrm{~kg}\end{array}$ & 0,40 \\
\hline & $\begin{array}{l}\text { Lapisan } \\
\text { pondasi } \\
\text { atas }\end{array}$ & 12,4 & 25 & $\begin{array}{l}\text { Batu } \\
\text { pecah } \\
\text { (kelas } \\
\text { A) }\end{array}$ & 0,14 \\
\hline & $\begin{array}{l}\text { Lapisan } \\
\text { pondasi } \\
\text { bawah }\end{array}$ & & 40 & $\begin{array}{l}\begin{array}{l}\text { Sirtu } \\
\text { (kelas } \\
\text { B) }\end{array}\end{array}$ & 0,12 \\
\hline
\end{tabular}

Perhitungan tebal lapis perkerasan dapat dihitung dengan menggunakan persamaan sebagai berikut:

$$
\begin{aligned}
& \text { Segmen }_{\text {rencana }}(\text { STA } 15+050-\text { STA } 15+500) \\
& \text { ITP }=\left(a_{1} \times D_{1}\right)+\left(a_{2} \times D_{2}\right)+\left(a_{3} \times D_{3}\right) \\
& 12,4=(0,40 \times 10)+(0,14 \times 25)+(0,12 \times \text { D3 }) \\
& \text { D3 }=\frac{12,4-(7,6)}{0,12} \\
& \text { D3 }=40 \mathrm{~cm}
\end{aligned}
$$

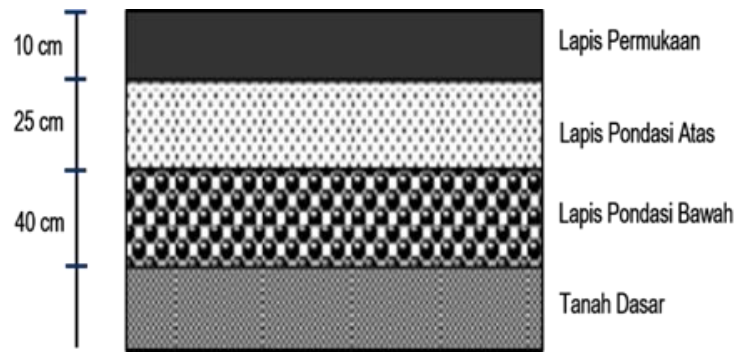

Gambar 2. Detail Tebal Perkerasan

\section{Analisa Rencana Anggaran Biaya}

a. Pekerjaan Persiapan Badan Jalan Baru

Volume $=$ (lebar lapis pondasi bawah $\mathrm{x}$

Panjang jalan)

$$
\begin{aligned}
& =3,5 \mathrm{~m} \mathrm{x} 450 \mathrm{~m} \\
& =1575 \mathrm{~m}^{2}
\end{aligned}
$$

b. Pekerjaan Bahu Jalan

$$
\begin{aligned}
\text { Volume } & =(\text { bahu jalan } \mathrm{x} \text { panjang jalan }) \\
& =2 \mathrm{~m} \times 450 \mathrm{~m} \\
& =900 \mathrm{~m}^{2}
\end{aligned}
$$

c. Pekerjaan marka jalan

Volume $=($ lebar marka $\mathrm{x}$ panjang jalan $)$

$$
\begin{aligned}
& =0,10 \mathrm{~m} \mathrm{x} 450 \mathrm{~m} \\
& =45 \mathrm{~m}^{2}
\end{aligned}
$$

d. Pekerjaan perkerasan jalan

- Lapisan pondasi Bawah (agregat kelas A)

$$
\begin{aligned}
& =3,5 \mathrm{~m} \mathrm{x} 0,23 \mathrm{~m} \mathrm{x} 450 \mathrm{~m} \\
& =362,25 \mathrm{~m}^{3}
\end{aligned}
$$

- Lapisan pondasi atas

$$
\begin{aligned}
& =3,5 \times 0,25 \mathrm{~m} \times 450 \mathrm{~m} \\
& =393,75 \mathrm{~m}^{3}
\end{aligned}
$$

- Lapis permukaan

$\circ$ Lapis resap pengikat

$$
=3,5 \mathrm{~m} \mathrm{x} 0,25 \mathrm{~m} \times 450 \mathrm{~m}
$$

$=393,75 \quad \mathrm{~m} \quad \mathrm{x} \quad 1,0 \quad$ liter $/ \mathrm{m}^{2}$ (penyemprotan aspal per $\mathrm{m}^{2}$ untuk pembukaan jalan baru)

$$
=393,75 \text { liter }
$$

$\circ$ Lapis perekat

$$
=3,5 \mathrm{~m} \mathrm{x} 0,06 \mathrm{~m} \times 450 \mathrm{~m}
$$

$=94,5$ liter 
- Laston

$$
\begin{aligned}
& =3,5 \mathrm{~m} \mathrm{x} 0,04 \mathrm{~m} \mathrm{x} 450 \mathrm{~m} \\
& =63 \mathrm{~m}^{3}
\end{aligned}
$$

\section{SIMPULAN}

Berdasarkan hasil perhitungan perencanaan jalan ruas jalan Petuk Kecamatan Penfui Kota Kupang STA $15+050-15+500$ dengan menggunakan perkerasan lentur dapat diperoleh kesimpulan bahwa perencanaan jalan dengan perkerasan lentur menggunakan Laston dengan tebal $10 \mathrm{~cm}$ dan tebal pondasi atas berupa batu pecah kelas A $25 \mathrm{~cm}$ beserta pondasi bawah sirtu kelas B $40 \mathrm{~cm} .3$. Rencana anggaran biaya untuk perencanaan jalan ruas jalan Petuk Kecamatan Penfui Kota Kupang (STA 15+050 - STA 15+500) adalah Rp 14,382,428,000.00 ( Terbilang Empat Belas Milyar Tiga Ratus Delapan Puluh Dua Juta Empat Ratus Dua Puluh Delapan Ribu Rupiah).

\section{UCAPAN TERIMAKASIH}

Ucapan terima kasih kepada Program Studi Teknik Sipil, Universitas Narotama Surabaya atas dukungan dalam penyelesaian penelitian ini.

\section{DAFTAR PUSTAKA}

Andriansyah. 2016. Optimalisasi Tebal Perkerasan Pada Pekerjaan Pelebaran Jalan dengan Metode MDPJ 02/M/BM/2013 dan Pt T-012002-B. Universitas Lampung. 2016

Budiono, 2012, (Analisis Kerusakan Jalan Dengan Metode PCI dan Alternatif Penyelesaiannya (Studi Kasus Ruas Jalan Purwodadi -Solo Km $12+000-\mathrm{Km} 24+000)$, Skripsi Teknik Sipil Universitas Muhammadiyah Surakarta.

Kementerian Pekerjaan Umum Direktorat Binamarga 2017. Manual Desain Perkerasan 2017.

Kementerian Pekerjaan Umum, 2002, Pedoman Perencanaan Tebal Perkerasan Lentur Pt T-012002-B, Badan Penerbit Pekerjaan Umum, Jakarta.

Shirley L. Hendarsin,2000, Perencanaan Teknik Jalan Raya, Penerbit Politeknik Negeri Bandung Jurusan Teknik Sipil,Bandung.

Sri Wiwoho, Sigit and Arthur, Universitas Muhammadiyah Jakarta. 2017. Sistim Pakar Pemilihan Model Perbaikan Perkerasan lentur Berdasarkan Indeks Kondisi Perkerasan (PCI).

Sukirman Silvia, 1999,Perkerasan Lentur Jalan Raya, Penerbit Nova, Bandung. 